\title{
I.C.LERCHER
}

\section{Kariesdiagnostik und Composite-Darstellung}

\author{
Die Firma I.C.LERCHER bietet Mitgliedern des Freien Verbandes Deutscher Zahnärzte ein \\ Angebot zum Sonderpreis.
}

Diagnostikset Göttingen auf White-LED und UV-LED Basis Die Kaltlicht-Diagnostiksonde „Göttingen" mit speziellem Anschliff wurde zur Früherkennung von Approximalkaries entwickelt. Klinische Studien beweisen, dass mit Hilfe der Transillumination mehr als doppelt so viele kariöse Defekte entdeckt werden als mit Spiegel und Sonde. Und sogar im Vergleich zu Röntgenuntersuchungen wird mit der Faseroptik mehr Dentinkaries sichtbar gemacht, wie Studien von Prof. Dr. Pieper belegen.

Der Handgriff wurde weiter entwickelt: Ein Wechselaufsatz ermöglicht nun ein einfaches Austauschen der WHITE-LED und der UV-LED.

Der neue UV-LED-Lichtaufsatz bietet die Möglichkeit, Komposite sichtbar zu machen. Diese Technik ermöglicht es, unerwünschte Materialreste sowohl beim Legen als auch beim Entfernen von Kompositen sichtbar zu machen.

Das Diagnostikset bestehend aus:
- Handgriff aus hochwertigem Edelstahl

- Wechselaufsatz mit WHITE-LED

- Diagnostiksonde Göttingen

- Diagnostiksonde Standard

- Wechselaufsatz mit UV-LED (optional)

\section{Sonderpreis für Verbandsmitglieder}

250,75 Euro statt 295,00 Euro

UV-Aufsatz für Diagnostikset

Sonderpreis für Verbandsmitglieder 72,25 Euro statt 85,00 Euro

Sie können das Diagnostikset mit Hilfe des Service-Coupons auf DFZ-Seite 105 bestellen oder einfach auf unserer Homepage www.dynadent.de.

Lieferung:zzgl. MwSt. und sieben Euro Versand

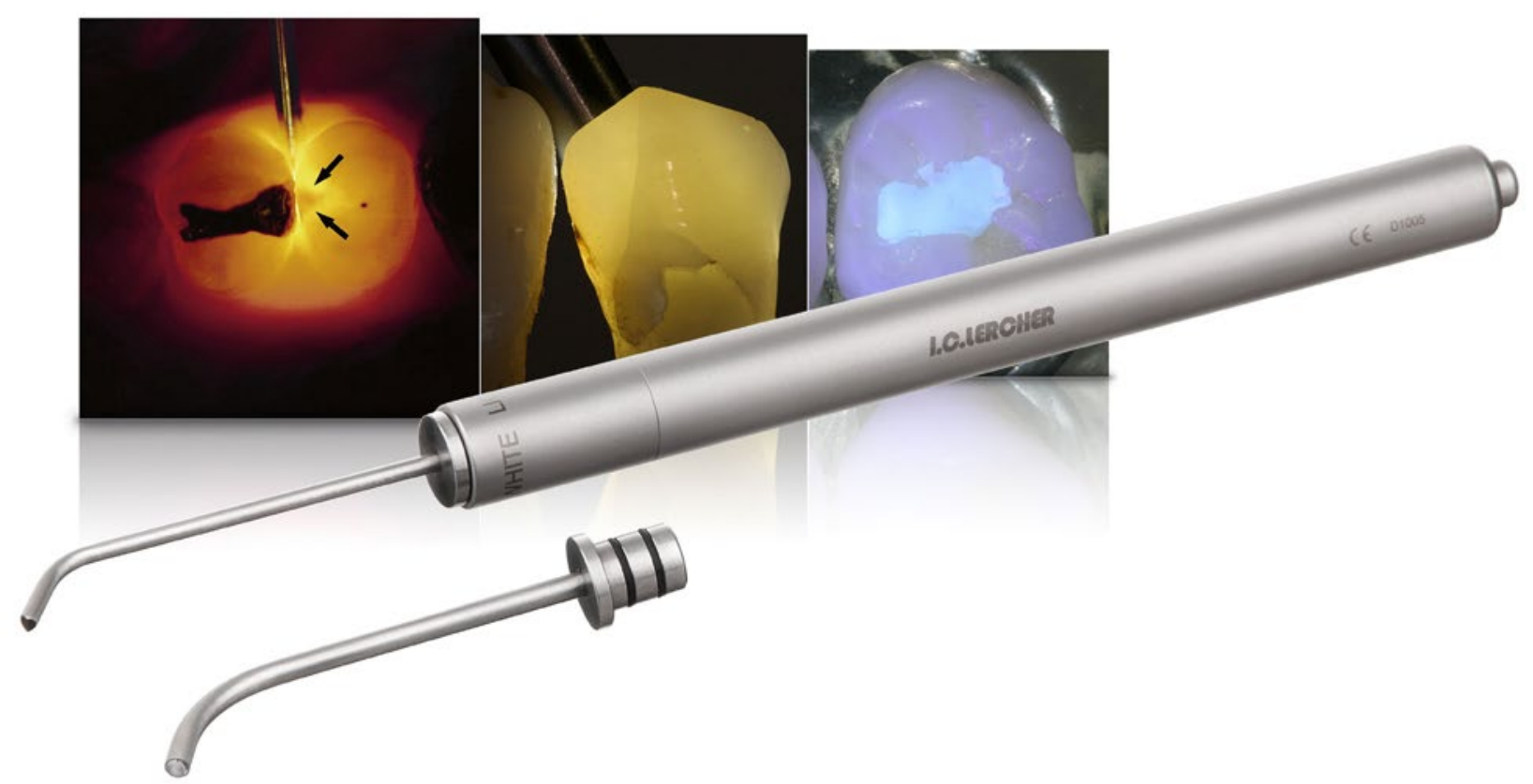

